\title{
AUGMENTED REALITY UNTUK MATERI BANGUN RUANG MENGGUNAKAN UNITY 3D, VUFORIA SDK DAN APLIKASI BLENDER
}

\author{
Rahmat $^{1)}$ dan Novi Yanti ${ }^{2)}$ \\ 12)Jurusan Teknik Informatika, Fakultas Komputer dan Multimedia, \\ Universitas Islam Kebangsaan Indonesia \\ e-mail: rahmat.mtk88@gmail.com
}

\begin{abstract}
[Augmented Reality for Space Building Materials Using Unity 3D, Vuforia SDK and the Blender Application] This research has tittle Augmented Reality for Building Materials using Unity 3D, Vuforia SDK, and Blender Applications. The development of information and communication technology has an impact on globalization which will affect all aspects of human life, especially in the world of education. This requires educators to make innovation in learning. One of the innovations that following technological developments, namely Augmented Reality (AR). Augmented Reality is a technique of combining real and virtual worlds and is based on 3-Dimensions (3D). The objects used can be 2D or 3D. In this research, the application were developed by involving three main software, namely vuforia, unity $3 \mathrm{D}$, and Blender. Vuforia is a plugin for a software called unity 3D. Augmented Reality and Unity 3D are two platforms that make it easier for users to produce 3D graphics that will be displayed if the graphic that has been used as a marker was shot with a camera from a SmartPhone. The difficulty in making 3D shapes was on forming and designing 3D shapes in the blender application. This research was successfully developing applications with building markers using vuforia, unity 3D, and Blender. The form of 3-dimensional shapes was successfully presented in Augmented reality by using these three applications. The suggestion from this research was to create more specific 3D space shapes so when the marker display was shot by the Android camera, the number of edges and also the volume formula from the shape could be seen.
\end{abstract}

Keywords: Database; Marker; Software.

\begin{abstract}
Abstrak
Perkembangan teknologi informasi dan komunikasi berdampak pada globalisasi yang akan mempengaruhi segala aspek dalam kehidupan manusia, khususnya dalam dunia pendidikan. Hal ini menuntut pendidik untuk membuat suatu inovasi terbaru dalam pembelajaran. Salah satunya inovasi yang sesuai dengan perkembangan teknologi yaitu Augmented Reality (AR). Augmented Reality merupakan teknik penggabungan dari dunia nyata dan virtual serta berbasis 3-Dimensi (3D). Objek-objek yang digunakan dapat berupa 2D ataupun 3D. Penelitian ini berjudul Augmented Reality untuk Materi Bangun Ruang menggunakan Unity 3D, Vuforia SDK, dan Aplikasi Blender. Pada penelitian ini, aplikasi dikembangkan dengan melibatkan 3 software utama yaitu vuforia, unity $3 \mathrm{D}$, dan Blender. Vuforia merupakan sebuah plugin dari software yang bernama unity 3D. Augmented Reality dan unity 3D adalah dua platform yang memudahkan pengguna untuk menghasilkan grafik 3D yang akan ditampilkan jika grafik yang telah dijadikan marker disorot dengan kamera dari sebuah SP. Kesulitan dalam pembuatan bentuk 3D yaitu dalam membentuk dan mendesain bentuk 3D di aplikasi blender. Hasil penelitian ini berhasil mengembangkan aplikasi dengan marker bangun ruang menggunakan vuforia, unity 3D, dan Blender. Bentuk bangun ruang 3-dimensi berhasil disajikan dalam Augmented reality dengan menggnakan ketiga hasil tersebut. Berdasarkan hasil penelitian dapat disimpulkan bahwa Augmented reality berhasil dikembangkan dengan marker bangun ruang menggunakan aplikasi vuforia, unity 3D, dan Blender. Adapun saran dari penelitian ini yaitu pembuatan bangun ruang 3D yang lebih spesifik sehingga saat tampilan marker disorot oleh kamera android dapat terlihat jumlah rusuk dan juga rumus volume dari bangun ruang.
\end{abstract}

Kata Kunci: Database; Marker; Software. 


\section{Pendahuluan}

Augmented Reality atau dalam bahasa indonesia diterjemahkan menjadi realitas tambahan adalah sebuah teknik yang menggabungkan benda maya dua dimensi maupun tiga dimensi kedalam lingkup nyata tiga dimensi lalu memproyeksikan benda-benda maya tersebut dalam waktu nyata. Dengan bantuan alat seperti smartphone atau tablet yang bersistem android maupun iOS dengan pemanfaatan fitur kamera dunia 3D yang dirancang dengan perangkat komputer dapat ditampilkan sebagai pop up object (Pamoedji \& Maryuni, 2017). Pengguna AR dapat berinteraksi langsung atau tidak langsung dengan dunia nyata secara bersamaan menggunakan komputer/gadget secara virtual untuk mengeksplorasi informasi (Adami \& Budihartanti, 2016). Informasi-informasi tentang objek dan lingkungan sekitar kita dapat ditambah dalam sistem AR, kemudian informasi tersebut ditampilkan diatas layer dunia nyata secara real-time (Azuma, 1997). Tampilan dari AR sendiri merupakan penggabungan benda-benda nyata dan maya di lingkungan nyata yang berjalan secara interaktif dalam waktu nyata (real time) dimana benda maya terintegrasi dalam dunia nyata (Chen, Liu, Cheng, \& Huang, 2017). AR bertujuan menyederhanakan hidup pengguna dengan membawa informasi virtual tidak hanya untuk lingkungan sekitarnya, tetapi juga untuk setiap pandangan tidak langsung dari lingkungan dunia nyata. Dengan bantuan teknologi AR, lingkungan nyata disekitar kita akan dapat berinteraksi dalam bentuk virtual (Kusuma, 2018; Mustaqim, 2016). AR dapat berfungsi sebagai kacamata atau proyektor retina yang menyediakan tampilan informasi yang relevan, diperlihatkan ke lingkungan secara real time (Maulana, 2017).

Perkembangan AR juga sudah mulai popular di bidang pendidikan. AR telah berkembang sejak 2 dekade dan terus diterapkan di berbagai bidang pendidikan seperti kedokteran, IPA, teknik bahkan bahasa asing bahkan dalam mempelajari sejarah. Tujuan dari AR adalah mengambil dunia nyata sebagai dasar dengan menggabungkan beberapa teknologi virtual dan menambahkan data kontekstual agar pemahaman manusia sebagai penggunanya menjadi semakin jelas (Boyles, 2017). Teknologi AR ini telah banyak digunakan dalam berbagai bidang terutama dibidang game. Selain di bidang game AR juga banyak dimanfaatkan untuk membantu visualisasi perangkat guna mempermudah proses pengerjaan seperti dalam dunia rancang bangun robot, kontruksi, pemasaran produk, dan dunia pendidikan (Haryani \& Triyono, 2017; Kurnia, 2019; Raharjo \& Pitaloka, 2020).

Pembelajaran bangun ruang, biasanya hanya berupa gambar yang terbatas pada bahan ajar baik buku ataupun modul. Buku atau modul pembelajaran dapat dibuat lebih interaktif, kreatif, menarik, dan inovatif. Peserta didik dapat mempelajari dan memahami materi, serta dapat melihat animasi pembelajaran dengan adanya bantuan dari AR. Animasi pembelajaran dibangun menggunakan aplikasi blender dan pembangunan AR menggunanakan Unity 3D dan Vuforia SDK.

Blender adalah sebuah perangkat lunak animasi 3D yang padat, lintas platform yang gratis dan dapat digunakan oleh masyarakat pengguna komputer yang umum yang berkembang sejak Tahun 1995. Blender yang merupakan perangkat kreasi 3D bersifat gratis dan open source. Blender medukung seluruh alur kerja 3D seperi modeling, rigging, animasi, simulasi, rendering, compositing dan motion tracking, bahkan pengeditan video dan pembuatan game. Blender sangat cocok digunakan oleh perseorangan maupun oleh studio kecil yang bermanfaat dalam proyek 3D (Waeo, Lumenta, \& Sugiarso, 2016).

Unity 3D merupakan software untuk membangun permainan 3-dimensi yang telah terintergrasi untuk menghasilkan suatu animasi 3 dimensi secara real time. Unity juga memiliki Integrated Development Environment (IDE) yaitu Mono Develop yang bertujuan untuk mengintegrasikan semua script yang dibuat kedalam unity, sehingga dapat langsung diproses. Unity 3D dikembangkan oleh Unity Technologies yang dibangun di Tahun 2004 oleh David Helgason, Nicholas Francis dan Joachim Ante. Pada Tahun 2009, unity diluncurkan secara gratis saat ini jutaan developer telah terdaftar dari seluruh dunia.

Aplikasi AR yang telah dibangun dapat digunakan dalam perangkat android sehingga dapat diinstall dalam smartphone terintegrasi android. Perangkat smartphone sangat dekat dengan kehidupan saat ini. Selain sebagai fungsi komunikasi, perangkat smartphone juga sangat berpotensi dikembangkan menjadi media pembelajaran interaktif yang bermanfaat bagi peserta dididik, karena teknologi bukan lagi dianggap sebagai sesuatu yang baru. Sehingga dengan pemakaian smartphone bisa dimanfaatkan untuk media dalam pembelajaran, salah satunya Augmented Reality dalam proses pembelajaran. Peserta didik dapat meningkatkan pemahaman matematika melalui bahan ajar yang terintegrasi AR dalam proses pembelajaran. Beberapa penelitian terkait penerapan AR dalam pembelajaran juga telah dilakukan, diantaranya penelitian oleh Lahallo, Wiranatha, and Sasmita (2016) yang merancang pembelajaran tentang molimod yang menemukan bahwa pembelajaran di SMA menjadi lebih menarik dan siswa lebih aktif. Sedangkan Adami and Budihartanti (2016) menerapkan teknologi AR pada media pembelajaran sistem pencernaan.

\section{Metode}

Penelitian ini merupakan jenis penelitian Research and Development (R\&D). Model penelitian yang digunakan adalah ADDIE (Analyze, Design, Development, Implementation, Evaluation). 
1. Tahap Analisis Kebutuhan

Pada tahap analisis, dilakukan proses kajian literatur untuk memperoleh informasi software sebagai alat pengembangan yang digunakan.

2. Tahap Desain

Pada tahap ini dilakukan perancangan konsep model media yang ingin dikembangkan.

3. Tahap Pengembangan

Pada tahap ini desain dibangun kedalam program software.

4. Tahap Implementasi

Pada tahap ini merupakan tahap membangun scene marker dan bentuk 3D hasil pengembangan ke aplikasi Unity 3D.

5. Tahap Evaluasi

Tahap ini merupakan tahapan pengujian software yang digunakan yang bertujuan untuk memastikan hasil yang diperoleh sesuai keinginan dengan kesalahan yang sangat kecil.

Aplikasi AR dikembangkan dengan melibatkan 3 software utama yaitu vuforia, unity 3D dan blender. Vuforia merupakan sebuah plugin dari software yang bernama unity 3D. Augmented Reality dan unity 3D adalah dua platform yang memudahkan pengguna untuk menghasilkan grafik 3D yang akan ditampilkan jika buku/modul berisi marker disorot dengan kamera dari sebuah Smart Phone (SP).

\section{Hasil dan Pembahasan}

Penelitian ini diawali dengan analisis kebutuhan. Analisis dilakukan dengan melakukan kajian literatur. Kajian literatur dilakukan dengan mengumpulkan data terkait software yang dapat digunakan. Hasil dari tahapan analisis ini yaitu penggunaan software Unity 3D, Vuforia SDK, dan blender. AR secara umum merupakan kombinasi dari dunia nyata serta virtual dan berbasis 3D. Objek-objek yang digunakan dapat berupa 2D ataupun 3D. Objek tersebut diproyeksi ke dunia nyata dalam waktu yang nyata (real time). Informasi yang diproyeksi dapat dimanfaatkan untuk membantu user dalam melakukan kegiatan-kegiatan dalam dunia nyata.

Sistem AR memiliki tiga komponen utama yaitu, Tracking system menentukan posisi dan orientasi objek-objek dalam dunia nyata. Graphic system yang menggunakan informasi yang disediakan tracking system untuk menggambarkan gambar-gambar virtual pada tempat yang sesuai, sebagai contoh melalui objek-objek nyata. Kemudian display system yaitu tampilan system yang menggabungkan dunia nyata dengan gambar virtual dan mengirimkan hasilnya pada pengguna (Kustiawan, 2009) dalam (Mubai, Rukun, Tasrif, \& Huda, 2020).

Adapun tahapan awal dari desain dimulai dengan penentuan marker/trigger yang akan digunakan, kemudian dilajutkan dengan membuat bentuknya ke dalam bentuk 3D. Proses pembuatan aplikasi AR diperlukan sebuah marker sebagai penanda untuk menampilkan suatu objek. Marker yang digunakan pada aplikasi Augmented Reality ini ialah Marker Based Tracking. Marker diperlukan dalam bentuk file gambar dengan ekstensi .JPG yang nantinya akan diunggah ke situs resmi Vuforia. Vuforia merupakan Software Development Kit (SDK) yang disediakan oleh Qualcomm untuk membantu para developer membuat aplikasi-aplikasi Augmented Reality (AR) di mobile phones (IOS dan Android). Vuforia menggunakan teknologi komputer vision untuk mengenali dan melacak gambar plannar (image target) dan objek 3D sederhana secara realtime (Cushnan dan Habbak, 2013). Vuforia merupakan perpustakaan yang digunakan sebagai pendukung adanya Augmented Reality pada Android dan iOS. Vuforia menganalisa gambar dengan menggunakan pendeteksi marker dan menghasilkan informasi 3D dari marker yang sudah dideteksi via Application Programming (API). Programmer juga dapat menggunakannya untuk membangun objek 3D virtual pada kamera. Tampilan marker yang telah diunggah dalam situs vuforia dapat dilihat pada Gambar 1 . 


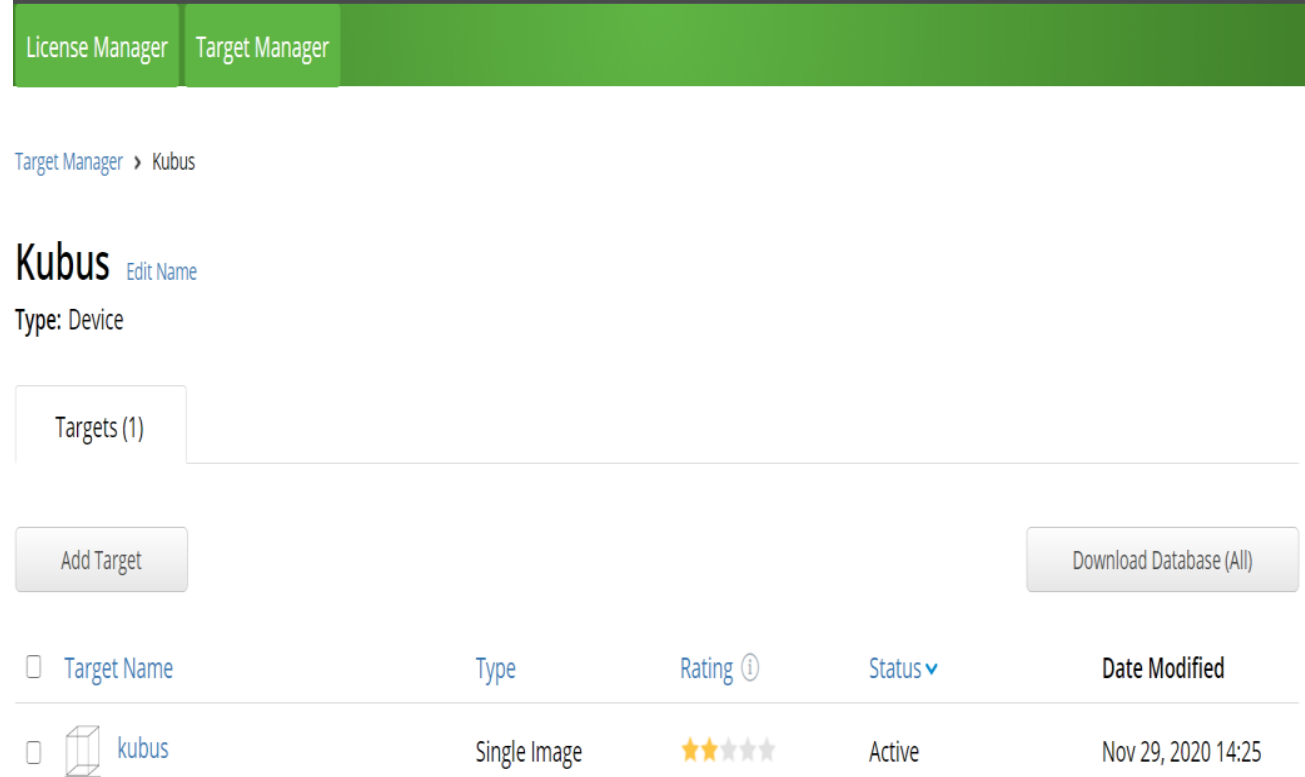

Gambar 1. Marker kubus yang diunggah dalam situs resmi Vuforia.

Marker yang telah diunggah kedalam situs Vuforia SDK akan dinilai kualitasnya oleh sistem. Semakin banyak rating dengan tanda bintang yang diberikan, maka kualitas marker akan semakin baik. Langkah selajutnya setelah marker diunggah dalam situs vuforia yaitu pembuatan molekul 3D menggunakan software khusus dalam pembuatan benda-benda dalam bentuk 3D. Sorftware yang digunakan dalam penelitian ini yaitu software Blender. Blender merupakan aplikasi untuk pembuatan molekul 3D. Tampilan bentuk 3D kubus yang dibuat menggunakan aplikasi blender dapat dilihat pada Gambar 2.

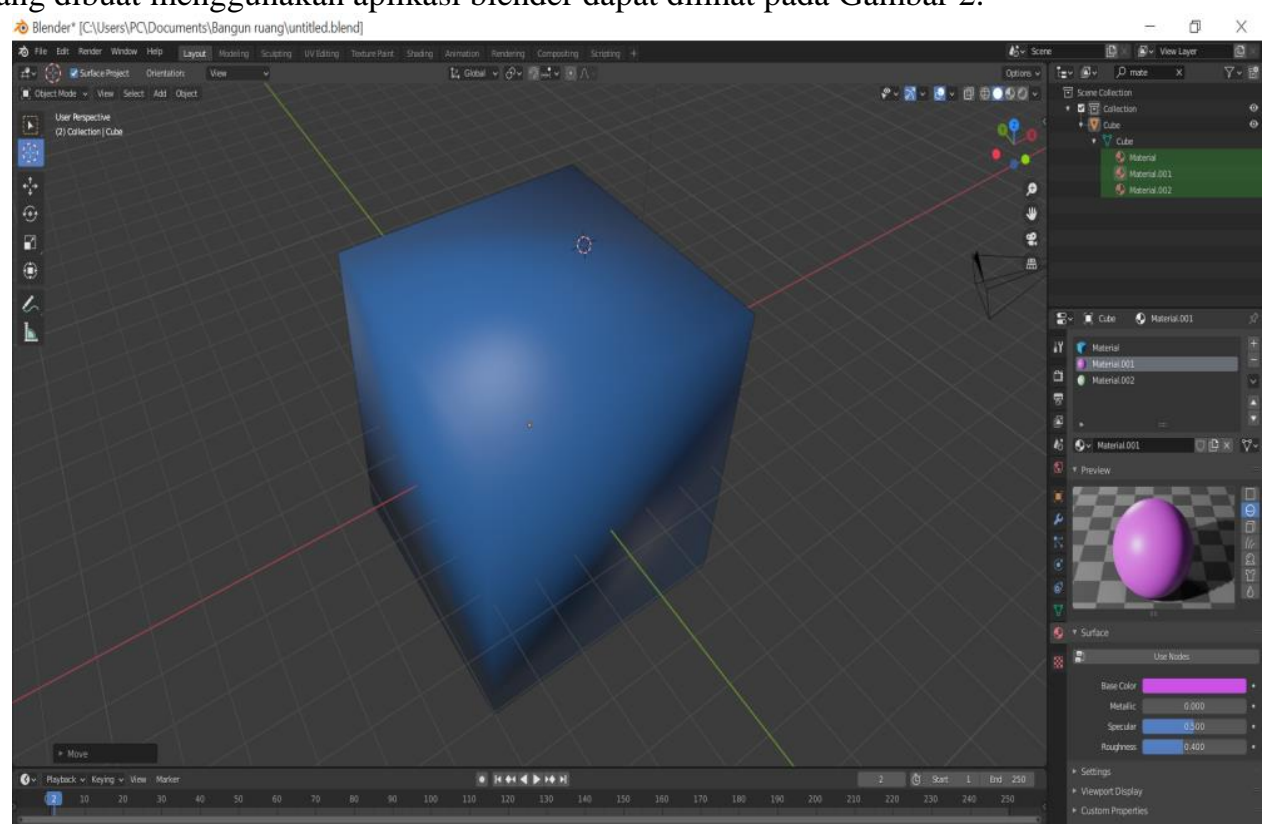

Gambar 2. Bentuk 3D Kubus yang dibuat menggunakan aplikasi blender.

Kesulitan dalam pembuatan bentuk 3D yaitu dalam membentuk dan mendesain bentuk 3D di aplikasi blender. Hal ini menyebabkan karena proses pembuatan bentuk 3D membutuhkan waktu yang lama, sehingga membuat proses pembuatan aplikasi AR cukup memerlukan waktu. Setelah marker dan bentuk 3D selesai didesain, dilanjutkan dengan mendesain aplikasi di software Unity 3D. Unity 3D sendiri merupakan alat yang digunakan untuk membangun games 3 dimensi yang telah terintergrasi untuk menghasilkan suatu animasi 3 dimensi secara real time. Software Unity 3D dilengkapi dengan GUI (Graphical User Interface) yang memudahkan untuk membuat, mengedit dan membuat script untuk menciptakan sebuah game 3D. 
Langkah pertama yang dilakukan dalam Unity 3D adalah memasukkan marker kubus yang telah diunggah dalam Vuforia ke dalam scene di Unity 3D. Tampilan marker dalam scene Unity 3D disajikan pada Gambar 3 berikut.

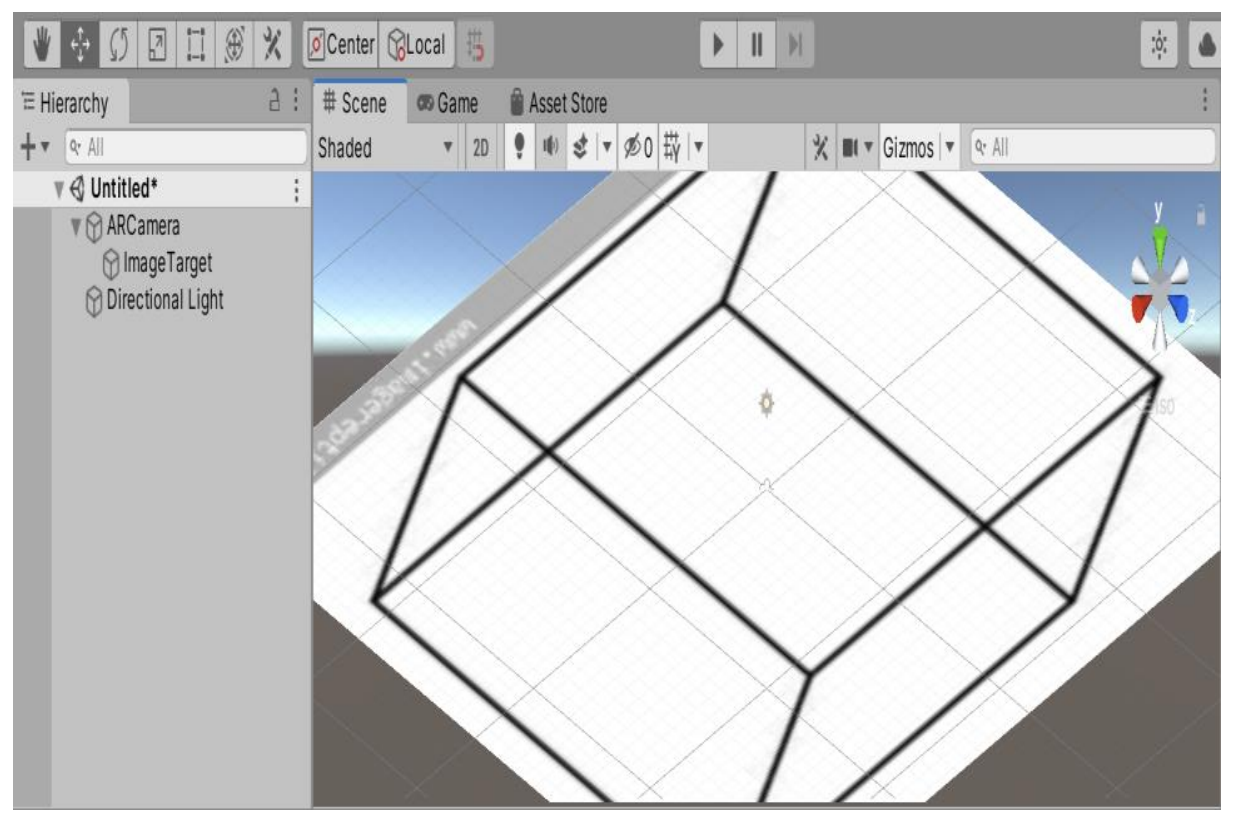

Gambar 3. Tampilan marker kubus dalam scene Unity 3D.

Selanjutnya, setelah marker kubus berhasil dimasukkan dalam scene Unity 3D, dilakukan build untuk bentuk 3D diatas marker. Adapun tampilan hasil build marker dan bentuk 3D dari kubus dalam Scene Unity 3D disajikan pada Gambar 4.

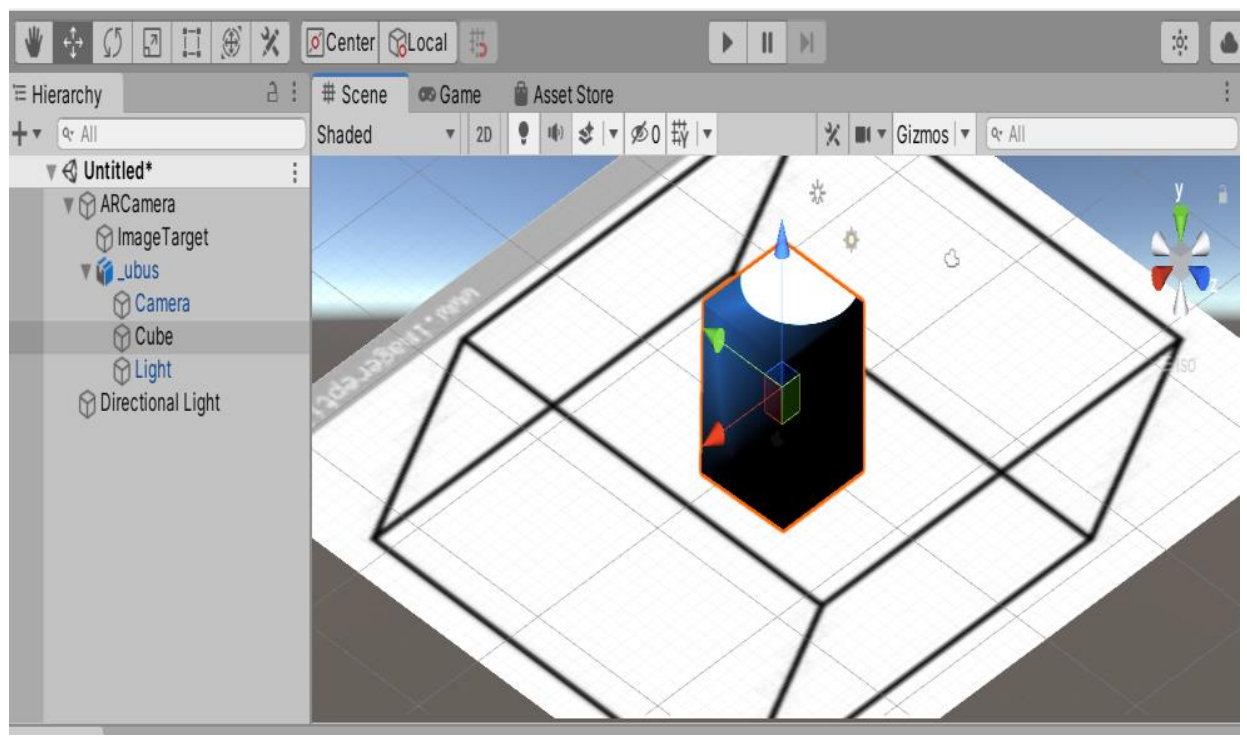

Gambar 4. Hasil build marker dan bentuk 3D dari kubus dalam Scene Unity 3D.

Tahapan selanjutnya adalah mengubah hasil built pada Gambar 4 menjadi file berekstensi Android Package (APK) yang dapat diinstall dalam smartphone terintegrasi android. Tampilan pengubahan file menjadi file .APK disajikan pada Gambar 5 berikut. 


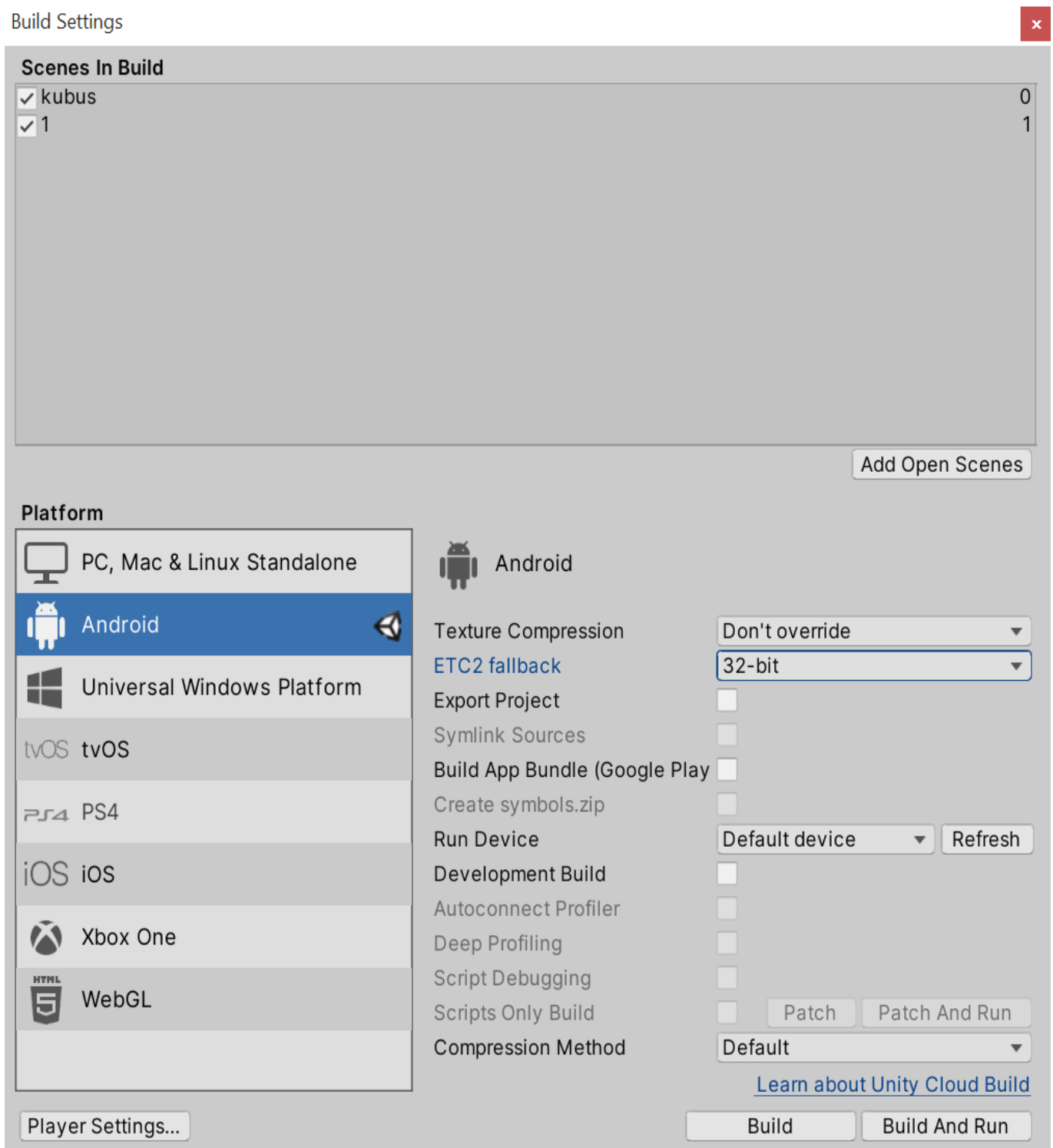

Gambar 5. Tampilan pengubahan file menjadi file .APK.

Untuk membuat aplikasi AR dapat digunakan dalam perangkat android, perlu dilakukan development aplikasi android dengan menggunakan Android Studio yang menghasilkan file berekstensi Android Package (APK) yang dapat diinstall dalam smartphone terintegrasi android. Build berguna untuk membangun aplikasi yang telah dirancang didalam Software tersebut, sehingga dapat digunakan di Handphone android yang sering dipakai oleh masyarakat sekitar. Setelah di build, aplikasi dapat langsung digunakan/ diinstall di handphone android dan dapat langsung digunakan.

\section{Kesimpulan}

Adapun kesimpulan dari hasil penelitian ini yaitu:

1. AR yang dikembangkan dapat menampilkan bentuk 3-Dimensi bentuk bangun ruang yang mirip dengan bentuk nyata.

2. Hasil penelitian ini berhasil mengembangkan aplikasi dengan marker bangun ruang menggunakan vuforia, unity 3D, dan Blender.

3. Adapun saran dari penelitian ini yaitu pembuatan bangun ruang 3D yang lebih spesifik sehingga saat tampilan marker disorot oleh kamera android dapat terlihat jumlah rusuk dan juga rumus volume dari bangun ruang. 
Rahmat - Augmented Reality untuk Materi Bangun Ruang Menggunakan Unity 3D, Vuforia SDK, dan

\section{Daftar Pustaka}

Adami, F. Z., \& Budihartanti, C. (2016). Penerapan Teknologi Augmented Reality pada Media Pembelajaran Sistem Pencernaan Berbasis Android. Jurnal Teknik Komputer, 2(1), 122-131.

Azuma, R. T. (1997). A survey of augmented reality. Presence: Teleoperators \& Virtual Environments, 6(4), 355-385.

Boyles, B. (2017). virtual reality and augmented reality in Education. Center For Teaching Excellence, United States Military Academy, West Point, Ny.

Chen, P., Liu, X., Cheng, W., \& Huang, R. (2017). A review of using Augmented Reality in Education from 2011 to 2016 Innovations in smart learning (pp. 13-18): Springer.

Haryani, P., \& Triyono, J. (2017). Augmented Reality (Ar) Sebagai Teknologi Interaktif Dalam Pengenalan Benda Cagar Budaya Kepada Masyarakat. Simetris: Jurnal Teknik Mesin, Elektro dan Ilmu Komputer, 8(2), 807-812.

Kurnia, D. (2019). Rancang bangun robot pemadam api menggunakan kontrol Bluetooth dan Virtual Reality. UIN Sunan Gunung Djati Bandung.

Kusuma, S. D. Y. (2018). Perancangan Aplikasi Augmented Reality Pembelajaran Tata Surya dengan Menggunakan Marker Based Tracking. Jurnal Informatika Universitas Pamulang, 3(1), 33-38.

Lahallo, C. A. S., Wiranatha, A. K. A. C., \& Sasmita, I. G. M. A. (2016). Media Pembelajaran Molymod Senyawa Hidrokarbon Teknologi Augmented Reality Berbasis Android. Jurnal Ilmiah Merpati (Menara Penelitian Akademika Teknologi Informasi).

Maulana, G. G. (2017). Penerapan Augmented Reality Untuk Pemasaran Produk Menggunakan Software Unity 3D Dan Vuforia. Jurnal Teknik Mesin Mercu Buana, 6(2), 74-78.

Mubai, A., Rukun, K., Tasrif, E., \& Huda, A. (2020). Augmented Reality (AR)-Based Learning Media on the Subject of Computer Network Installation. Jurnal Pendidikan dan Pengajaran, 53(2), 213-226.

Mustaqim, I. (2016). Pemanfaatan Augmented Reality sebagai media pembelajaran. Jurnal Pendidikan Teknologi dan Kejuruan, 13(2), 174-183.

Pamoedji, A. K., \& Maryuni, R. S. (2017). Mudah Membuat Game Augmented Reality (AR) dan Virtual Reality (VR) dengan Unity 3D: Elex Media Komputindo.

Raharjo, N. E., \& Pitaloka, G. K. (2020). PENGEMBANGAN MEDIA PELAJARAN BERBASIS APLIKASI ANDROID DENGAN AUGMENTED REALITY UNTUK MATA PELAJARAN GAMBAR TEKNIK KELAS X KONTRUKSI GEDUNG, SANITASI DAN PERAWATAN DI SMK NEGERI 1 SEYEGAN. Jurnal Pendidikan Teknik Sipil, 2(1), 65-77.

Waeo, V., Lumenta, A. S., \& Sugiarso, B. A. (2016). Implementasi Gerakan Manusia Pada Animasi 3D Dengan Menggunakan Menggunakan Metode Pose to pose. Jurnal Teknik Informatika, 9(1). 